\title{
Design software and technological solutions subsystem job scheduling for custom passenger transportation during XXII Olympic Winter Games
}

\section{Ismailov Andrey Rashidovich}

Russian Federation, Ph.D., Head of the department of development planning and monitoring systems. JSC "NPP Transnavigatsiya", 103051, Russian Federation, Moscow, B. Carriage Lane, 21, build. 1, Tel.: +7 (495) 783-54-85. http://www.transnavi.ru

aklerk@gmail.com

\section{Lvova Anna Bogdanovna}

Russian Federation, master of engineering and technology specialist.

JSC "NPP Transnavigatsiya", 103051, Russian Federation, Moscow, B. Carriage Lane, 21, build. 1, Tel.: +7 (495) 783-54-85. http://www.transnavi.ru

\section{ne-smotri-nalevo@yandex.ru}

\section{Ostroukh Andrey Vladimirovich}

Russian Federation, full member RAE, Doctor of Technical Sciences, Professor, Department of «Automated Control Systems».

Moscow Automobile \& Road construction State Technical University, 125319, Russian Federation, Moscow, Leningradsky prospekt, 64. Tel.: +7 (499) 151-64-12. http://www.madi.ru

ostroukh@mail.ru

\begin{abstract}
This paper proposes an approach to the formation of software and technology solutions for the creation of job scheduling subsystem for custom-made passenger in the automated system of dispatching custom transportation.

Based on the study of foreign experience of the use of computer-based navigation systems in passenger services in the future form the requirements for establishing, within a subsystem of the passenger transport automated control system Logistics Transportation Center (LTC ACS).
\end{abstract}

Keywords: automated control system (ACS), process modeling and information processing systems, methods and management tools in the transport sphere, modeling, identification. 
ISSN 2306-1561

Автоматизация и управление в технических системах (АУТС) 2014. - №1.1(8). - C. 98-111.

DOI: $10.12731 / 2306-1561-2014-1-11$

УДК 004.9: 656.025

\section{Проектирование программно-технологических решений подсистемы планирования заданий для заказных перевозок пассажиров при проведении XXII Зимних Олимпийских Игр}

\section{Исмаилов Андрей Рашидович}

Российская Федерация, кандидат технических наук, начальник отдела разработки систем планирования и мониторинга.

ЗАО «НПП Транснавигация», 103051, Российская Федерация, г. Москва, переулок Каретный Б., д. 21, стр. 1, Тел.: +7 (495) 783-54-85. http://www.transnavi.ru

\section{aklerk@gmail.com}

\section{Львова Анна Богдановна}

Российская Федерация, магистр техники и технологии, специалист.

ЗАО «НПП Транснавигация», 103051, Российская Федерация, г. Москва, переулок Каретный Б., д. 21, стр. 1, Тел.: +7 (495) 783-54-85. http://www.transnavi.ru

\section{Остроух Андрей Владимирович}

Российская Федерация, академик РАЕ, доктор технических наук, профессор кафедры «Автоматизированные системы управления».

ФГБОУ ВПО «Московский автомобильно-дорожный государственный технический университет (МАДИ)», 125319, Российская Федерация, г. Москва, Ленинградский проспект, д.64, Тел.: +7 (499) 151-64-12, http://www.madi.ru

\section{ostroukh@mail.ru}

Аннотация. В статье предложен подход к формированию программнотехнологических решений по созданию подсистемы планирования заданий для заказных перевозок пассажиров в составе автоматизированной системы диспетчерского управления заказными перевозками.

На основе исследования зарубежного опыта использования автоматизированных навигационных систем транспортного обслуживания пассажиров в дальнейшем формируются требования для создания в рамках подсистемы управления пассажирским 
транспортом (ПУПТ) автоматизированной системы управления Логистического транспортного центра (АСУ ЛТЦ).

Ключевые слова: автоматизированные системы управления (АСУ), моделирование процессов и систем обработки информации, методы и средства управления в области транспорта, моделирование, идентификация.

\section{1. Введение}

Организация Олимпийских Игр - является сложной, комплексной задачей. Подготовка крупнейшего спортивного события зимой 2014 г. в г. Сочи ведется по 54 направлением, одним из которых является транспортное обеспечение всех участников и гостей Олимпиады.

Специально для XXII Зимних Олимпийских Игр была разработана модель улично-дорожной сети Сочи. Также было проведено моделирование уровней загрузки основных узлов транспортной системы; сформированы маршрутные сети для обслуживания Олимпиады (общего пользования и специальные - для аккредитованных лиц и групп); осуществлено моделирование пассажирских потоков в сформированных маршрутных сетях для всех дней Олимпиады и участков транспортной системы, определены пиковые значения пассажирских нагрузок в период проведения Олимпийских Игр [1].

В основе общего описания организации и управления транспортом, обслуживающим гостей и участников Олимпийских Игр лежит интермодальный подход, то есть совместное использование нескольких видов транспорта [2]. Общая концепция системы управления интермодальными перевозками ориентирована на то, что прибытие зрителей, персонала и участников Игр будет осуществляться с использованием возможностей железнодорожного, авиа, автомобильного и водного видов транспорта, а передвижение между олимпийскими объектами осуществляется при помощи железнодорожного и автомобильного видов транспорта, а так же канатной дороги.

При проведении столь массового мероприятия крайне важным является процесс перевозки и доставки к олимпийским объектам аккредитованных лиц, которые подразделяются на клиентские группы [3].

\section{2. Анализ структуры автоматизированных навигационных систем транспортного обслуживания пассажиров}

Подсистема планирования заказных перевозок (ППЗП) относится к подсистеме управления пассажирским транспортом в области заказных перевозок (ПУПТ «ПО Заказных перевозок»), реализуемой в составе подсистемы управления пассажирским транспортом (ПУПТ). В свою очередь ПУПТ является одной из составных частей единой автоматизированной системы управления Логистического транспортного 
центра (АСУ ЛТЦ), которая по виду автоматизируемой деятельности относится к системам приема, обработки и отображения информации [4].

Основными целями создания системы являются [10 - 28]:

- обеспечение высокого уровня качества транспортного обслуживания автомобильным олимпийским пассажирским транспортом представителей всех клиентских групп в период подготовки и проведения XXII Олимпийских зимних игр и XI Паралимпийских зимних игр в г. Сочи (своевременная доставка участников соревнований, зрителей и местного населения на объекты соревнований, прибытие и отбытие делегаций и официальных гостей, информационная поддержка процессов выделения необходимого количества транспортных средств определенного класса для соответствующих клиентских групп);

- обеспечение информационного взаимодействия и координации деятельности участников транспортной системы при заказе и резервировании транспорта;

- обеспечение информационного взаимодействия и поддержка основных бизнес-процессов по категории «Транспорт» в рамках интеграции с Единой идентификационной системой Олимпийских Игр (ЕИС);

- обеспечение информационного взаимодействия и координации деятельности участников пассажирских перевозок железнодорожным, автомобильным, морским, авиационным транспортом, канатными дорогами;

- обеспечение достоверности получаемой, обрабатываемой и хранимой информации, используемой в процессе деятельности Транспортной дирекции для организации бесперебойной доставки пассажиров в период подготовки и проведения XXII Олимпийских зимних игр и XI Паралимпийских зимних игр 2014 года.

ПУПТ АСУ ЛТЦ предназначена:

- для контроля безопасности и централизованного автоматизированного оперативного управления автомобильным пассажирским транспортом в период подготовки и проведения Олимпийских Игр;

- для автоматизации планирования, контроля и координации процессов работы Олимпийского пассажирского транспорта (ОПТ);

- для информационного взаимодействия с предприятиями и организациями, участвующими в работе олимпийских объектов, доставке пассажиров, а также подготовке и проведении XXII Олимпийских зимних игр и XI Паралимпийских зимних игр 2014 года.

ПУПТ «ПО ЗАКАЗНЫХ ПЕРЕВОЗОК» должна обеспечивать реализацию основных функций, отраженных на верхнем уровне функциональной схемы, представленной на рисунке 1. 


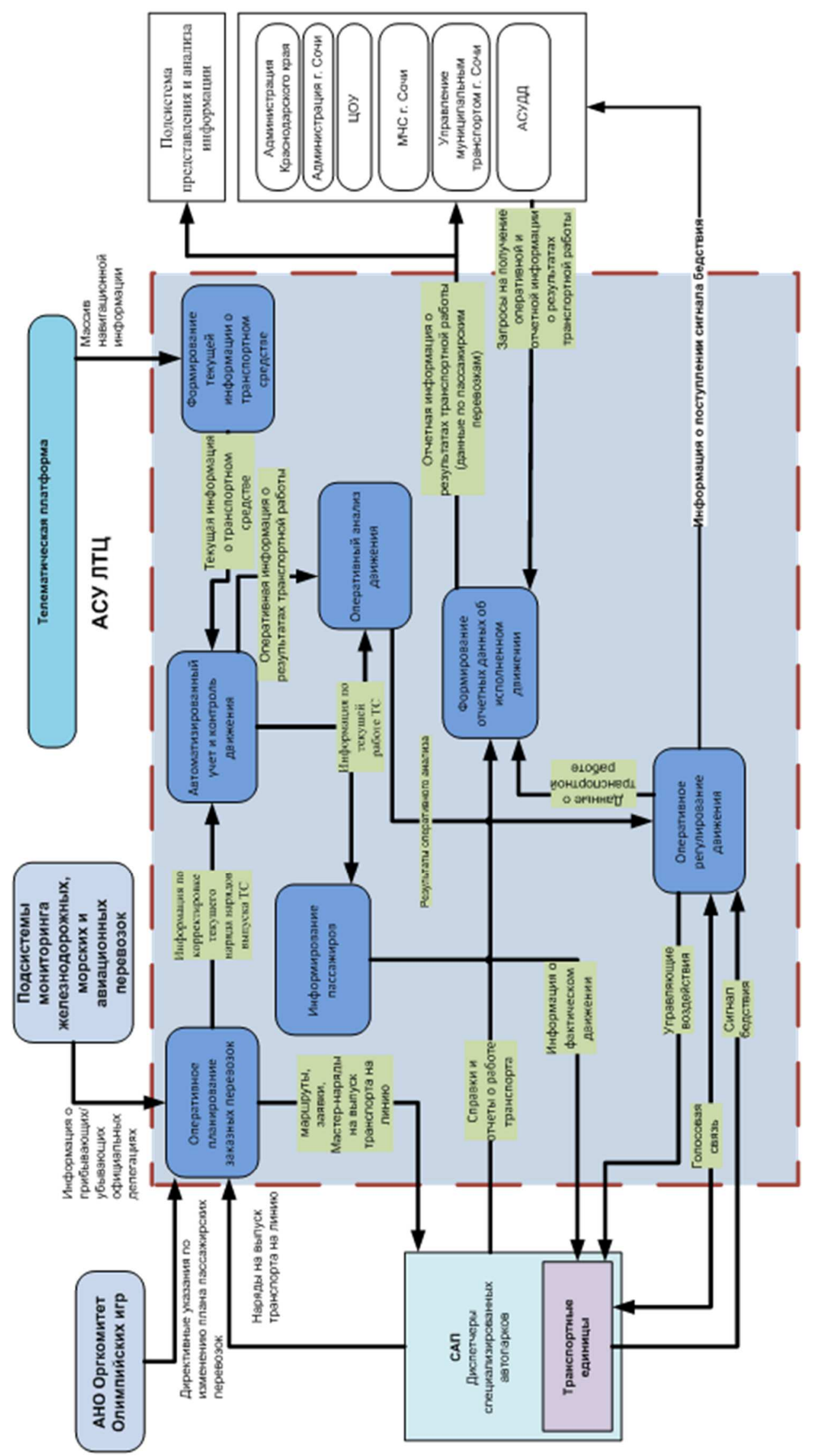

Рисунок 1 - Функциональная схема ПУПТ «ПО Заказных перевозок» 
Функции подсистемы управления пассажирским транспортом (ПУПТ) АСУ ЛТЦ г. Сочи должны реализовываться комплексом взаимосвязанных программ, опирающихся на единую информационную базу данных системы и использующих унифицированные протоколы обмена информацией между различными элементами системы.

ПУПТ АСУ ЛТЦ включает в себя подсистемы создания справочной информации, планирования перевозочного процесса, диспетчерского управления, обработки и анализа информации, а также административного управления. В данной работе будет рассмотрена подсистема планирования перевозочного процесса клиентских групп.

Самыми актуальными задачами на автомобильном транспорте являются задачи оперативного диспетчерского управления работой транспортных средств в режиме реального времени и учета фактически выполненной транспортной работы. Основными инструментами решения поставленных задач являются навигационные системы, используемые для оперативного управления движением и учета фактически выполненной транспортной работы. Внедрение навигационных систем на автомобильном транспорте направлено на решение следующих базовых задач [8 - 28]:

- Информационное обеспечение перевозок: формирование плана перевозок клиентских групп, формирование электронной карты города;

- Оперативное управление движением;

- Формирование и вывод оперативных справок и выходных отчетных форм в конце смены.

Технология диспетчерского управления транспортом на базе систем транспортной телематики можно представить в виде следующей схемы [5, 26, 27] (рисунок 2).

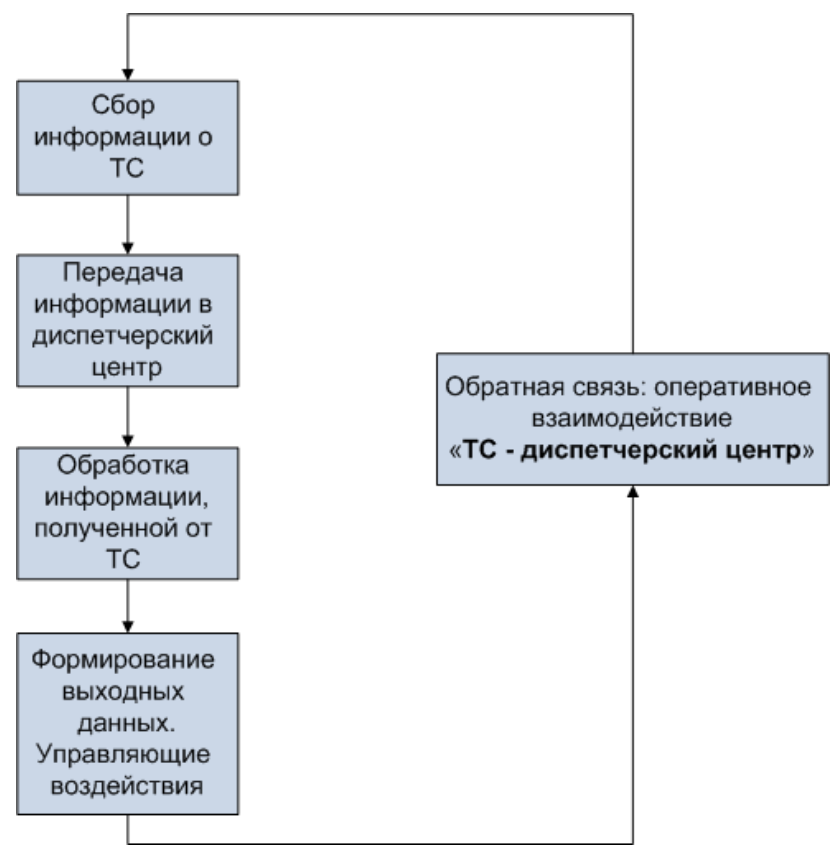

Рисунок 2 - Укрупненная схема технологии автоматизированного диспетчерского управления транспортом 
Рассмотрим каждый элемент представленной схемы подробнее.

\section{1. Сбор информации о транспортном средстве}

В зависимости от задач, стоящих перед системой диспетчерского управления тем или иным видом транспорта, варьируется перечень параметров транспортного средства, которые необходимо учитывать для формирования выходных данных, управляющих воздействий и т. д.

В основном, информацию, получаемую от транспортного средства, можно разделить на два блока:

- информация о местоположении транспортного средства (координаты, контрольные пункты, и т. д.);

- информация, характеризующая работу транспортного средства (дополнительно могут учитываться такие показатели, как расход топлива, состояние основных узлов и агрегатов).

В обоих случаях ТС нужно оснастить оборудованием, которое осуществляет сбор информации, поступающей как от датчиков, установленных на ТС, так и от навигационных блоков. Сбор информации о ТС производится периодически, в общем случае с интервалом в 30 секунд.

\section{2. Передача информации в ЛТЦ}

Передача оперативной и достоверной информации от транспортных средств в ЛТЦ при реализации функции управления транспортными средствами в режиме реального времени для повышения эффективности управления перевозочным процессом.

\section{3. Обработка информации, полученной от транспортных средств}

Информация от транспортных средств, полученная ЛТЦ, обрабатывается с помощью специализированного программного обеспечения.

\section{4. Формирование выходных данных, управляющих воздействий}

Формирование выходных данных позволяет анализировать выполненную транспортную работу за определенный период времени.

В основе функционирования автоматизированных навигационных систем лежит понятие контрольного пункта (КП) - некоторой области на местности, определяющей обязательный пункт прохождения ТС по маршруту следования. Они используются для определения фактических показателей процесса движения. В расчетах участвуют только навигационные отметки, поступившие в навигационную систему во время нахождения ТС в зоне КП. Остальные отметки используются только для определения фактического местоположения ТС и отображения его на электронной карте местности, но в расчетах не участвуют [6].

\section{3. Представление процесса организации транспортного обслуживания клиентских групп}

Для транспортного обслуживания клиентских групп созданы специальные автотранспортные парки (САП), с помощью которых выполняются перевозки гостей и участников Олимпийских Игр. Осуществляют перевозки клиентских групп различные 
группы перевозчиков - предприятий со своим парком ТС и группой водителей, которые предоставляют различным САП свои транспортные средства и водителей. Таким образом, в одном САП для перевозок клиентов могут быть доступны автомобили и автобусы различных перевозчиков. Предполагается, что создание нарядов на транспортное обслуживание клиентов должно производиться с указанием ТС и водителей одного и того же перевозчик, однако это не является строгим правилом.

Основными функциями САП являются транспортное обслуживание гостей олимпиады, своевременное оперативное предоставление парка транспортных средств ТДОИ, диспетчерское управление процессом выполнения транспортной работы и формирование нарядов на обслуживание клиентов [7, 20 - 23, 26]. В рамках САП работают следующие специалисты:

- диспетчер: выполняет мониторинг процесса движения транспорта, осуществляет диспетчерское управление транспортом (выход на связь, управление процессом движения, принятие решения в критических ситуациях)

- старший диспетчер;

- аналитик: формирует оперативную и/или суточную отчетно-аналитическую информацию;

- старший аналитик;

- технолог: ведет информацию в базу данных нормативно-справочной информации (НСИ);

- нарядчик: формирует суточные наряды на транспортное обслуживание клиентов.

Bсе вышеперечисленные специалисты имеют доступ к разрабатываемой автоматизированной навигационной системе, и при помощи нее будут осуществлять процесс транспортного обслуживания клиентских групп во время проведения олимпийских Игр.

Для автомобильных перевозок пассажиров необходимы два компонента: транспортные средства и водители. Каждый САП имеет определенное количество закрепленных за ним транспортных средств и водителей, которые не привязаны к какому-либо определенному ТС. По требованиям ОКОИ, при создании задания на обслуживание клиента, необходимо указывать САП, отвечающий за транспортировку пассажиров, однако указанные транспортные средства и водители могу относиться к другому САП.

Транспортные средства САП при выполнении транспортной работы проходят контрольные пункты. Многие их этих контрольных пунктов посещаются в определенном порядке. Таким образом, такой упорядоченной набор представляет собой маршрут движения. В разрабатываемой системе маршрут включает в себя не только информацию о списке КП, но и дополнительную технологическую информацию, такую как расстояние до следующего КП, время движения до следующего КП. Эти данные требуются для расчета показателей движения, таких как время начала и окончания 
транспортного обслуживания. Создаваемое задание на обслуживание может быть привязано к маршруту, на котором оно должно быть выполнено.

Согласно требованиям ОКОИ, для своевременного обеспечения транспортного обслуживания в момент проведения Олимпийских Игр, кроме Церемоний Открытия и Закрытия, необходимо располагать данными о резервном количестве машин. Данные транспортные средства осуществляют перевозку по требованию клиента, без предварительно сформированной заявки. Таким образом, у каждого транспортного средства должен быть признак наряда, по какой системе в какой день ТС работает: по требованию клиентов или по предварительной заявке.

Кроме того, ТС и водители могут быть закреплены за определенным контрагентом (клиентом) на все время проведения Олимпиады. Данные об этом содержаться в разделе справочной информации автоматизированной системы и должны быть доступны при создании задания на обслуживание.

Сами контрагенты отличаются об обычных гостей Олимпиады наличием аккредитации или апгрейд-карты. Заказные перевозки осуществляются только по заказу лица, сообщившего специалисту, создающему заявку на обслуживание, номер своей аккредитации или номер апгрейд-карты. В случае если указанный номер отсутствует в БД, происходит отказ в обслуживании данного гостя или участника Игр. При использовании номера аккредитация, для формирования заявки становятся доступны данные, указанные в аккредитации: фамилия, имя, отчество, должность, контактный телефон и пр. Апгрейд-карта, в отличие от аккредитации, выдается без указания идентифицирующих данных и может предоставляться как человеку, так и организации. Таким образом, при использовании номера апгрейд-карты для создания заявки на обслуживание, становится необходимым указать дополнительные данные о заказчике: контактное лицо, выступающее в качестве основного заказчика услуг, и его номер телефона.

Требованием ЛТЦ также является возможность указания в заявке, помимо КП, списка спортивных мероприятий, необходимых к посещению. При выборе мероприятия необходимо указывать вид спорта и соревнования, а также имя спортивного объекта, где будет происходить мероприятие.

В обобщенном виде схему работы системы можно описать следующим образом: в систему поступают заявки на транспортное обслуживание, которые могут приходить из различных источников: с транспортных стоек в аэропортах и на вокзалах, Web-портала или ОКОИ. С использованием специально созданной справочной информации, хранящейся в БД, данные заявки обрабатываются специалистами, и по результатам их обработки формируется план на перевозки клиентов - наряд. Более подробно процесс формирования заявок на транспортное обслуживание описан ниже. В процессе выполнения транспортной работы специалист-диспетчер может проводить мониторинг этого процесса и производить необходимые манипуляции. По результатам выполнения работы могут быть сформирован ряд информационно-аналитических отчетов. Данные отчетные формы должны включать в себя всю информацию, которая в полной мере может всестороннее отобразить, как проходил процесс формирования работ. 


\section{4. Математическая модель планирования транспортного обслуживания заказных перевозок}

Процесс планирования транспортного обслуживания можно представить в виде математической модели. Рассматривая процесс транспортного обслуживания в течение промежутка времени, например месяца, можно представить плановые задания в виде множества $P$, а количество созданных заданий за месяц будет равняться $m$. Получается, что

$|P|=m$.

По мере выполнения задания из плановых будут переходить в фактически выполненные. Необходимо также учитывать возможность появления выполненных заданий, которые до этого не были запланированы. Подобные задания могут возникать, например, в случае работы по некоторым транспортным системам, в частности Т1 и Т2, когда допустимо предоставление ТС с указанием только места посадки пассажира и без указания дальнейшего пути следования. Для обозначения всех фактически выполненных заданий необходимо ввести множество $F$.

В начале месяца задания еще отсутствуют, тогда

$P=\varnothing$,

$F=\varnothing$.

В течение промежутка времени заявки поступают в систему и составляют общий план на транспортное обслуживание:

$|P| \rightarrow m$.

У каждого элемента $i$ множества $P$ есть набор характеризирующих его атрибутов:

$P i<\{C P\}, t_{1}, t_{2},\{D\},\{V\} \ldots>$,

где $C P$ - множество контрольных пунктов,

$t_{1}$ - время начала выполнения задания,

$t_{2}$ - время окончания выполнения задания,

$D$ - множество водителей, выполняющих транспортное обслуживание по заданию,

$V$ - множество транспортных средств, указанных в задании.

У элементов множества фактически исполненных заданий имеется такой же набор атрибутов. Рассматривая все атрибуты как упорядоченные наборы элементов на основе теоремы о равенстве двух наборов одной длины в случае равенства их соответствующих элементов [6] можно сравнивать два множества $P$ и $F$.

Таким образом, пусть выполненные плановые задания составляют множество $P_{f}$ :

$P_{f}=\{\exists p \in P\}$,

где $p$ - выполненное задание.

Получается, что множество $P$ включает в себя множество $P_{f}$, являющееся подмножество $F$ (рисунок ЗОшибка! Источник ссылки не найден.):

$P_{f} \subset F$, 


$$
\begin{aligned}
& P_{f} \subset P, \\
& P_{f}=P \cap F .
\end{aligned}
$$

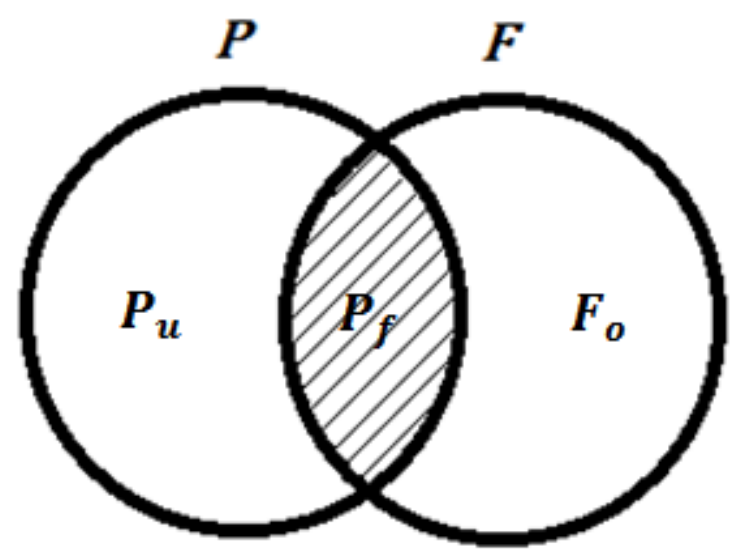

\section{Рисунок 3 - Диаграмма Эйлера-Венна для множеств Р и F}

Количество выполненных заданий может равняться общему количеству заданий или быть меньше:

$$
\begin{aligned}
& \left|P_{f}\right| \leq|P|, \\
& \left|P_{f}\right| \leq|F|,
\end{aligned}
$$

Невыполненные задания можно представить множеством $P_{u}$, которое является разностью множеств $P$ и $P_{f}$ :

$$
\begin{aligned}
& P_{u}=P \backslash P_{f}, \\
& \left|P_{u}\right| \leq|P| .
\end{aligned}
$$

Таким образом, все заявки в системе можно описать следующим отношением:

$$
\begin{aligned}
& P=P_{f} \cup P_{u}, \\
& |P|=\left|P_{f}\right|+\left|P_{u}\right| .
\end{aligned}
$$

Оставшиеся неучтенные в системе, но выполненные задания можно представить множеством $F_{o}$ :

$$
P_{o}=F \backslash P_{f} .
$$

Для общей оценки исполнения плана недостаточно оценки исполнения одних лишь заданий. В задании допускается наличие более одного исполнителя данного задания. Тогда возможны случаи, когда задание будет выполнено одними указанными в нем исполнителями, но не выполнено другими. Для оценки выполнения плановых заданий по исполнителям вводится понятие рейса - выполнение транспортного обслуживания одним водителем на выбранном ТС согласно плановому заданию.

Все возможные пары водитель/ТС, которые работали в течение рассматриваемого периода времени можно представить в виде декартова произведения множеств водителей $D$ и транспортных средств $V$ : 


$$
R_{V D} \subset V \times D \text {. }
$$

Множество выполненных рейсов может быть представлено с помощью отношения:

$$
R \subset P_{f} \times R_{V D}
$$

Тогда множество выполненных рейсов $R$ определяется следующим образом:

$$
R=\left\{\forall p \in P_{f} \wedge \exists r \in R_{V D} \text {, где } p R r\right\}
$$

a $p R r$ - выполняющие задание пары водитель/ТC.

Вышеперечисленные множества позволяют производить оценку эффективности транспортного обслуживания и в частности работу системы по планированию заданий на транспортное обслуживание.

\section{5. Заключение}

Проведено исследование предметной области. Проанализированы задачи, решаемые рассматриваемыми подсистемами; сформулированы требования, предъявляемые к их архитектуре. Также был проведен детальный анализ проектирования подсистемы планирования. Были выделены параметры задания и ряд ограничений и запретов, действующих при его создании.

Предполагается, что анализ предметной области, проведенный во время теоретических исследований, будет являться базисом для дальнейших экспериментальных исследований. В качестве эксперимента предложено создание программного обеспечения, соответствующего всем выработанным ранее требованиям.

\section{Список информационных источников}

[1] Официальный сайт АНО ТДОИ [Электронный ресурс]. / Пассажирские перевозки. 2011 г. Режим доступа: http://goo.gl/kIq8D.

[2] Пояснительная записка к проекту Постановления Правительства РФ: Об утверждении Правил организации перевозок грузов в целях строительства олимпийских объектов и развития города Сочи как горноклиматического курорта [от 12 апреля 2012].

[3] Транспортная дирекция Олимпийских Игр. Описание бизнес процессов деятельности подсистемы управления пассажирским транспортом на тестовых мероприятиях, проводимых на Олимпийских объектах в 2012-2013 годах. / ТДОИ, 2012. -55 c.

[4] Краюшкин А.Д. Описание постановки задач. Версия 2.3. 2010 - 37 с.

[5] Ефименко, Д.Б. Пояснительная записка. Том 1. Организация и управление интермодальными перевозками гостей и участников Олимпийских Игр/ Д.Б. Ефименко, В.Н. Богумил. - М, 2014 - 121 с.

[6] Principle Service Level Agreement (PSLA) Olympic Family/ SOCHI2014 Transport Department//Sochi. - 2012. - p.23

[7] Сычев П., Описание функций АНО «Оргкомитет Сочи 2014» [Электронный pecypc]. / 2012 г. Режим доступа: http://goo.gl/aEf8c.

[8] Лукащук П.И. Адаптивная методика прогнозирования пассажиропотоков в АСУ пассажирского автотранспортного предприятия / С. Бенгедаш, П.И. Лукащук, А.Г. 
Николаев, А.В. Остроух // Приборы и системы. Управление, контроль, диагностика. - М.: «Научтехлитиздат», 2006. - №11. - С. 7-11.

[9] Куфтинова Н.Г. Имитационное моделирование управления транспортными потоками в мегаполисе / А.В. Остроух, Н.Г. Куфтинова // Автотранспортное предприятие. - 2010. - №12. - С. 41-42.

[10] Польгун М.Б. Анализ моделей оперативного диспетчерского управления городским пассажирским транспортом / М.Б. Польгун, А.В. Воробьева, А.В. Остроух // Молодой ученый. - 2011. - №4. Т.3. - С. 9-13.

[11] Ефименко Д.Б. Автоматизированная навигационная система диспетчерского контроля и учета работы транспорта нефтедобывающих предприятий / А.И. Губанов, Д.Б. Ефименко, А.Б. Николаев, А.В. Остроух // Молодой ученый. - 2011. - №4. Т.3. - С. 18-21.

[12] Ефименко Д.Б. Развитие навигационной системы диспетчерского управления грузовым транспортом (на примере нефтедобывающих предприятий) / A.B. Остроух, Д.Б. Ефименко, С.А. Филатов // Автотранспортное предприятие. - 2011. №11. - С. 32-34.

[13] Ефименко Д.Б. Концепция автоматизированной навигационной системы диспетчерского контроля и учета работы транспорта нефтедобывающих и нефтеперерабатывающих предприятий / А.В. Остроух, А.Б. Николаев, Д.Б. Ефименко, А.И. Губанов // Автоматизация, телемеханизация и связь в нефтяной промышленности. - М.: ОАО «ВНИИОЭНГ», 2011. - №11. - С.12-14.

[14] Остроух А.В. Научный подход к разработке автоматизированной навигационной системы диспетчерского контроля и учета работы транспорта нефтедобывающих и нефтеперерабатывающих предприятий / А.В. Остроух, А.Б. Николаев, Д.Б. Ефименко, С.В. Жанказиев // Автоматизированные системы управления и приборы автоматики. - Харьков: ХНУРЭ, 2011. - Вып. 157. - С. 48-58.

[15] Порфирьева С.А. Автоматизированные информационные системы на автотранспортном предприятии / А.В. Остроух, К.А. Данчук, А.Б. Львова, С.А. Порфирьева, П.С. Якунин // В мире научных открытий. Серия «Проблемы науки и образования». - 2012. - №2.6 (26). - С.34-38.

[16] Ефименко Д.Б. Использование программного обеспечения радионавигационных диспетчерских систем для транспортного обслуживания специальных объектов нефтедобывающих компаний / А.В. Остроух, Д.Б. Ефименко, А.Б. Николаев, А.Р. Исмаилов // Автотранспортное предприятие. - 2012. - №2. - С. 42-44.

[17] Куфтинова Н.Г. Разработка информационно- логической модели транспортной сети мегаполиса / А.В. Остроух, Н.Г. Куфтинова // Бюллетень транспортной информации. - М.: Национальная ассоциация транспортников, 2013. - №1 (211). C. 23-26.

[18] Остроух А.В. Автоматизация процессов диспетчерского управления городским пассажирским транспортом / М.Б. Польгун, А.Б. Николаев, Д.Б. Ефименко, А.В. Остроух // Промышленные АСУ и контроллеры. - М.: «Научтехлитиздат», 2013. №5. - C. 10-16.

[19] Исмаилов А.Р. Разработка архитектуры подсистемы планирования организации заказных перевозок клиентских групп при проведении XXII зимних Олимпийских Игр / А.В. Остроух, А.Р. Исмаилов, А.Б. Львова // Бюллетень транспортной информации. - М.: Национальная ассоциация транспортников, 2013. - №12 (222). C. 3-10.

[20] Исмаилов А.Р. Автоматизированная система планирования заданий для заказных перевозок пассажиров при проведении Олимпийских Игр / А.В. Остроух, А.Р. 
Исмаилов, А.Б. Львова, А.Б. Николаев, П.Ю. Збавитель // Транспорт Российской Федерации. - 2013. - №6 (49). - С. 46-51.

[21] Исмаилов А.Р. Программно-технологические решения по разработке подсистем планирования заданий для заказных перевозок пассажиров при проведении Олимпийских Игр / А.В. Остроух, А.Р. Исмаилов, А.Б. Львова // Приборы и системы. Управление, контроль, диагностика. - М.: «Научтехлитиздат», 2013. №11. - С. 74-85.

[22] Николаев А.Б. Информационные технологии в менеджменте и транспортной логистике: учебное пособие / А.Б. Николаев, А.В. Остроух. - Saint-Louis, MO, USA: Publishing House Science and Innovation Center, 2013. - 254 c. - ISBN 978-0615-67110-9.

[23] Остроух А.В. Системы планирования перевозок. Программно-технологические решения по разработке системы планирования заданий для заказных пассажирских перевозок / А.В. Остроух, А.Б. Львова, А.Р. Исмаилов. Saarbrucken, Germany: LAP LAMBERT Academic Publishing, 2013. - 121 p. - ISBN 978-3-659-43619-2.

[24] Остроух А.В. Оперативный контроль транспортно-экспедиционной деятельности. Процессный подход к агрегированию системы показателей деятельности транспортно-экспедиционного предприятия / А.В. Остроух, А.М. Ивахненко, Н.А. Крупенский. - Saarbrucken, Germany: Palmarium Academic Publishing, 2013. - 221 p. - ISBN 978-3-659-98329-0.

[25] Польгун М.Б. Анализ структуры информационного обеспечения автоматизированных систем диспетчерского управления городским пассажирским транспортом // Автоматизация и управление в технических системах. - 2012. - № 1. - С. 129-135.

[26] Ismailov A., Lvova A., Nikolaev A., Ostroukh A. Organization and Management of Transport Provided for the Guests and Participants of the Olympic Games // MiddleEast Journal of Scientific Research. 2013. Vol. 17 (8). pp. 1098-1104. DOI: 10.5829/idosi.mejsr.2013.17.08.12300.

[27] Ostroukh A.V., Polgun M.B. Automation of processes supervisory control urban passenger transport // International Journal of Advanced Studies (iJAS). 2013. Vol. 3, Issue 3, pp. 3-9. DOI: 10.12731/2227-930X-2013-3-1.

[28] Ostroukh A.V., Polgun M.B. New approaches to development of automated supervisory systems of industrial enterprises transport // International Journal of Advanced Studies (iJAS). 2013. Vol. 3, Issue 4, pp. 3-9. DOI: 10.12731/2227-930X-2013-4-1. 